\title{
A Study on Teacher-Child Interaction from the Perspective of Children
}

\author{
Siqi Wang*, Hongjia Guo \\ Jilin Engineering Normal University, Changchun 130052, Jilin Province, China \\ *Corresponding author: Siqi Wang, 441438653@qq.com
}

\begin{abstract}
Children's perspective is based on their own cognitive level in understanding objective things. The study of children's perspective is a bottom-up research process under the premise of having a full respect for a child's view. With the change of views about children in recent years, "children's perspective" has become a new research direction. At the same time, teacher-child interaction, as an important means of evaluating the quality of kindergarten education, requires a bottomup perspective from children. This study hopes to understand children's emotional experience in the process of teacher-child interaction as well as their understanding and evaluation of their own experience by exploring their perspectives on the interaction, so as to better improve the quality of teacher-child interaction in kindergarten.
\end{abstract}

Keywords: Children's perspective; Teacher-child interaction

Publication date: December 2021; Online publication: December 27, 2021

\section{Background}

After sorting out relevant literatures, it has been found that current local research on teacher-child interaction is mostly conducted from the perspective and standards of adults, who use observation, recording, and other methods; then, using the quality scale to evaluate. However, there are several studies that take children as the main body to evaluate the behavior, mode, and content of teacher-child interaction. With the rise and development of theories and practices, such as the children's rights movement, learning stories in New Zealand, and Reggio's educational practice, the status of children in research has also changed. Through the research on preschool education quality from the perspective of children, it is possible to appreciate the disadvantages of the traditional adult discourse system. Children are the main body of educational activities, and their feelings about educational activities are of great significance to improve teaching methods and teaching strategies. Only by understanding the key factors affecting the quality of teacher-child interaction from the perspective of children, more education and teaching strategies can be put forward for front-line preschool teachers to improve their daily teaching practice.

\section{Literature review}

At present, there are several studies that are directly related to teacher-child interaction from the perspective of children. The initial study of teacher-child interaction from the perspective of children is actually by White KM, who included a child's perspective to her study on teacher-child interaction. She used continuation stories to guide children in such a way to express their views on teacher-child interaction in a fixed context, providing a new perspective for the study of teacher-child interaction ${ }^{[1]}$.

In recent years, scholars in China have been conducting research on the interaction between teachers and children from the perspective of children. In the same manner, Wang Xiaoying and Zhu Huihui analyzed the interaction between teachers and children from the perspective of children and studied the 
behaviors initiated by children in life situations during teacher-child interactions from their perspective. Through the statistical analysis of the frequency and causes of the behavior initiated by children, it has been concluded that the factors that affect the behavior of children from the perspective of children include spacetime factor, teacher factor, and children's psychological factor ${ }^{[2]}$. Through role-playing and using the grounded theory, Gao Yang has carried out a concrete research on teacher-child interaction from a child's perspective ${ }^{[3]}$. Through data collection and analysis, the research made a comprehensive analysis on the inner needs of children in teacher-child interaction. Seven specific inner needs of children have been determined, such as the need for communication and companionship, the need for self-realization, as well as the need for games and entertainment. According to the research results, the specific inner needs of children require teachers to fully consider the various needs of children in the interaction process and interact with children in various situations based on understanding their needs, in order to effectively improve the quality of teacher-child interaction.

Although there are only several studies on teacher-child interaction from the perspective of children, there are many studies on teachers through the eyes of young children. For example, A Survey on the Standards of Good Teachers in Children's Eyes by Dailey, A Good teacher in the Eyes of Children - A Study on the Quality of Teachers from the Perspective of Children by Yangcui, Research on the Ideal Teacher Image in Children's Mind by Li Xiaohang, and so on. Although these studies did not directly study the interaction between teachers and children from the perspective of children, they offered relevant experience in terms of research ideas and methods for this study, validating that there is a possibility to explore more on teacher-child interaction from the perspective of children as it has certain research value.

\section{Method and process}

For this research, 27 children aged 5-6 years from class 2 of kindergarten D in Changchun were selected as the research subjects.

First of all, the painting analysis method was used to analyze the children's painting. The children were guided through the painting process with questions, such as "Do you all have your favorite teacher?", "What is your favorite teacher like?", and "What stories did you have with your teacher?". The children were encouraged to draw based on the questions raised and to ensure that "teacher and I" or "teacher and children" could be visualized in their drawings. According to the children's description of their paintings, several points that the children were concerned about have been sorted out. On this basis, an outline for an interview was constructed.

According to the outline, a semi-structured interview was conducted for the children. The interview was mainly about what the children wanted to express, so the topics constantly expanded. The children were not only required to answer "yes" or "no" questions, but they were encouraged to express their own understanding and ask questions. By assuming the role of a friend during the interview, the behaviors and reasons for the interaction with their teachers were targeted, and the reasons for the children to be "doing this and not that" were understood.

The collected data were then coded and summarized.

\section{Results}

In this study, from the children's perspective, teacher-child interaction lacks emotional communication in terms of the content; in addition, their interactions are mostly teacher-led, even the language used is mainly controlled by the teacher. Through this research, there are several factors that affect teacher-child interaction from the perspective of children. 


\subsection{Teacher-child relationship affects the quality of teacher-child interaction from the perspective of children}

For some children, teachers often play the role of a "class commander" with absolute power. They restrain children in all aspects, establish rules, and punish those who violate the rules. This behavior often leads to poor emotional experience among children; moreover, they are placed in a situation where they have to obey against their own will. As a result, children would think that teacher-child interaction is only limited to "I do what the teacher says." This affects children in such a way that they would reconsider an active interaction with their teachers in the future.

\subsection{Children's own needs affect their evaluation of teacher-child interaction}

The tendency to favor teacher-initiated interaction and the kind of teacher-child interaction that the child chooses depend on whether the interaction can meet the needs of the child to some extent. That is to say, whether there is fondness in the evaluation of a child on teacher-child interaction initiated by teachers or whether self-initiated interaction is necessary according to the evaluation from a child are closely related to the child's own needs. In this study, from the teacher-initiated teacher-child interaction behavior, it was found that children are fond of emotional communication interaction, game interaction, as well as affirmation and support interaction because these interactions are able to meet their needs to varying degrees, whereas exclusive discipline and restraint interaction does not only forgo their needs, but also brings a negative impact on those needs that have already been met.

\subsection{Influence of "imaginative rehearsal" on whether and how children initiate teacher-child interactions}

Before initiating any interaction, children would rehearse by themselves while imagining how their teachers would respond to their interaction behaviors. They would then decide on whether to interact and how to interact. Most uninitiated interactions are the result of children's inference from "imaginative rehearsal" that their teachers' response may be to ignore or criticize them, resulting in a "dare not speak" situation. "Imagination rehearsal" plays an important role in regulating teacher-child interactions and has an important relationship with previous interactions between teachers and children.

\subsection{Constraints of gender impression and "self" image on teacher-child interaction from children's perspective}

To a certain extent, gender stereotyping affects children's perception of teacher-child interaction. By making cards or bows during art classes, boys would generally think that "this is what girls like." On the other hand, girls generally think that "weapons" and "soldiers" are associated with boys. Most children are more interested in activities that fit their gender stereotypes in teacher-child interactions.

At the same time, children between the ages of 5 and 6 are in Senior Class of kindergarten which is the stage when they are about to enter primary schools. Accordingly, children begin to adjust themselves from upper Middle Class to preparatory Senior Class. It can be seen that under the influence of this mature "self" image, children's requirements on themselves would improve, including their emotions, knowledge, and life skills; in addition, it is easier for them to understand the interactive behaviors of their teachers.

\section{Educational countermeasures}

\subsection{Establish correct views and attach importance to emotional communication with children}

As children in the Senior Class of kindergarten would be stepping into primary schools, preschool teachers 
would tend to focus on cultivating knowledge and habits. In the eyes of the children, their teachers have transformed from a "surrogate mother" to a more serious image as a "knowledge imitator." In order to improve teacher-child relationship, preschool teachers should first strengthen the emotional communication with children, use gentle tone, smile more often, and have close physical contact with them. This would help them feel the love from the teachers. In this manner, trust can be developed, and they would be able to interact better with their teachers.

As one of the important aspects in teacher-child interaction, it should not be forgotten that children are also independent individuals. From a child's perspective, teachers often decide what the child should learn, play, and do every day; in simple terms, a child's daily life is completely decided by the teachers. Children can only obey and follow the requirements set by the teachers; there are very few opportunities for independent thinking and discovery. Therefore, teachers should first establish correct views toward children and education, realize that children are the subject of education, fully respect the will of children, and highlight the status of children in various activities held in kindergarten.

\subsection{Effectively meet the needs of children}

In this study, "afraid" and "dare not" were the most frequently used words by the children. It can be seen that in daily kindergarten teaching activities, children are reprimanded and punished by teachers for various reasons. Even without any personal experience, it is impossible to have not seen any children being punished. This act of punishment affects children's psychology, building a sense of crisis among children. Therefore, preschool teachers should pay attention to how they usually punish children. When a child does wrong, the teacher should take appropriate measures to tell the child that his or her behavior is wrong; the teacher should not intimidate, beat, or excessively scold the child.

At the same time, most teachers do not seriously listen to the needs of children. When they do not understand the real needs of children, teacher-child interaction may be inefficient or ineffective. Preschool teachers should pay more attention to observing children through their behaviors to discover the reasons behind those behaviors and understand what they really want. At the same time, when problems occur, timely and patient communication is necessary, in order to better interact with children.

\subsection{Rational use of "imaginative rehearsal"}

General praises from teachers such as "you are wonderful" and "you are an obedient child" do not reinforce good behavior for most children. Teachers should praise specifically on a certain behavior, so as to strengthen the link between the behavior and the happy emotion experienced by the child. In this manner, children would be able to develop positive "imaginative rehearsal" of similar behavior.

\subsection{Help children establish correct gender image and "self" image}

A kindergarten is a service for a small group of children. Being at the kindergarten for the whole day, children, whether boys or girls, may experience anger, depression, or grievances. Teachers should not excessively emphasize on gender. For example, just because it is a boy, in order to cultivate the so-called "manly temperament," teachers should not force the child to suppress his emotions as it is very detrimental to the child's physical and mental health. On the other hand, by educating girls by saying that girls are meant to be clean or that girls have to be quiet may cause similar problems for them.

The study also found that not all children are able to restrain their behaviors to act as a "good child" or "older child." For children, the criteria for being a "good child" come from the outside world, including literatures and audio-visual products, in addition to the guidance of teachers and parents. The "self" image that should be in the heart of children is constructed from multiple perspectives, so preschool teachers 
should make use of multiple resources in the process of helping children to build their image. For example, the brave hero in the story and the loving children in the cartoon can all become examples for children and a benchmark for the concept of a "good child."

\section{Funding}

This research was supported by Jilin Province Vocational Education and Adult Education Teaching Reform Research Project (2021ZCY338) - Research on the Application of Blended Teaching Mode for Preschool Education Majors in Higher Vocational Schools - Take "Kindergarten Games" as an Example and Jilin Engineering Normal University School-Level Scientific Research Projects (Public List XII) - "Chinese and Foreign Preschool Education History" Course Thinking and Practice.

\section{Disclosure statement}

The authors declare that there is no conflict of interest.

\section{References}

[1] White KM, 2016, My Teacher Helps Me: Assessing Teacher-Child Relationships from the Child's Perspective. Journal of Research in Childhood Education, 30(1): 29-41.

[2] Wang X, Zhu H, 2017, A study of Young Children's Action Giving Behavior and Its Influencing Factors in Teacher-Child Interaction Based on Children's Perspective. Journal of Sichuan Normal University (Social Science Edition), 2017(11): 34-36.

[3] Gao Y, 2017, A Study of Teacher-Child Interaction from the Perspective of Young Children: A Case Study of Kindergarten A's Big Two Class in Kunming. Yunnan Normal University, 2017(5): 44-47. 